\title{
Anesthetic practices for patients with preeclampsia or HELLP syndrome: A survey
}

\author{
Betül Başaran ${ }^{1}$, Bilge Çelebioğlu ${ }^{3}$, Ahmet Başaran², Seher Altınel ${ }^{4}$, Leyla Kutlucan ${ }^{1}$, James N. Martin Jr ${ }^{5}$ \\ 'Department of Anesthesiology, Konya Training and Research Hospital, Konya, Turkey \\ ${ }^{2}$ Department of Obstetrics and Gynecology, Konya Training and Research Hospital, Konya, Turkey \\ ${ }^{3}$ Department of Anesthesiology, Hacettepe University School of Medicine, Ankara, Turkey \\ ${ }^{4}$ Department of Anesthesiology, Ankara Gazi Mustafa Kemal State Hospital, Ankara, Turkey \\ ${ }^{5}$ Department of Obstetrics and Gynecology, The University of Mississippi Medical Center, Jackson, USA
}

\begin{abstract}
Objective: Substantial controversy exists regarding anesthetic management for patients with preeclampsia or hemolysis, elevated liver enzymes, low platelet count (HELLP) syndrome. Experts, researchers, clinicians, and residents in Turkey were surveyed about their practices.

Material and Methods: Questionnaires were distributed to attendees at a national conference, and they were filled out immediately. Anonymous 10-item paper surveys were administered to both residents and non-residents. Descriptive statistics were used in the analysis. Agreement among $\geq 75 \%$ of the respondents was considered a majority opinion. Surveys with missing responses were used to analyze the non-response bias. The Chisquare test was used for comparisons. A historical cohort of obstetricians-gynecologists was used for comparison with anesthesiologists.

Results: Of 339 surveys distributed, 288 were returned ( $84.9 \%$ response rate). Among the returned surveys, the completion rate was $96.1 \%$. The job experience in years among clinicians and residents was $9 \pm 5$ and $3 \pm 1$, respectively. General anesthesia was still significantly preferred by $36.1 \%$ among patients with preeclampsia with platelet counts of $\geq 100,000 / \mu \mathrm{L}$. Compared to obstetricians-gynecologists, anesthesiologists more often preferred general anesthesia. With platelet counts of $<50,000 / \mu \mathrm{L}$ or eclampsia, most respondents preferred general anesthesia $94.4 \%$ for very low platelets and $89.5 \%$ for eclampsia.

Conclusion: A preferential trend toward general anesthesia for patients with preeclampsia or HELLP syndrome exists among anesthesiologists in Turkey, particularly for patients with severe thrombocytopenia and/or eclampsia. There exists a need for well-designed and well-executed prospective clinical trials to provide evidence for the best consensus practice. (J Turk Ger Gynecol Assoc 2016; 17: 128-33)
\end{abstract}

Keywords: Anesthesia, platelet count, glucocorticoids, HELLP syndrome, preeclampsia, survey

Received: 9 May, 2016 Accepted: 20 July, 2016

\section{Introduction}

Severe preeclampsia and hemolysis, elevated liver enzymes, low platelet count (HELLP) syndrome (hemolysis, elevated liver enzymes, low platelet count) are life-threatening complications during pregnancy (1). Complications and underlying etiopathogenesis of both preeclampsia and HELLP syndrome are globally associated with severe maternal morbidity and mortality. The two syndromes often involve multiple organ systems, including the mother's vasculature and her liver, lungs, kidney, and brain (1). Hence, concerted efforts to enhance the management of these disorders are vital to reduce, to the maximum extent possible, both maternal and fetal morbidity and mortality.

Despite significant advances in our understanding of both preeclampsia and HELLP syndrome, numerous unknowns remain and several controversial issues persist regarding etiology, diagnosis, and best practice management. The literature concerning the two syndromes is extensive but often conflictive. As part of the clinical paradigm, safe and evidence-based anesthetic management of at-risk patients in the peripartum period is of critical importance. When high-grade evidence is lacking, controversy exists. The choice of the anesthetic method is largely dictated by the composite condition of patients with preeclampsia, their platelet counts, and their coagulation statuses. With a focus on these issues, a cohort of anesthesiologists, including residents and clinicians, was surveyed to solicit their opinions and practice patterns.

\section{Material and Methods}

A 10-item paper survey was developed to query potentially controversial practices in the anesthetic management of patients with preeclampsia and/or HELLP syndrome. No respondents were compensated for this survey, consisting of single answer multiple-choice questions. Beyond the resident and practice experience questions, additional information about respondents was not requested and surveys were not paired with the clinician or resident, so that survey responses remained anonymous. 
The questionnaires were distributed to attendees at the Turkish Anesthesiology and Reanimation Association 2014 Annual meeting and were filled out immediately. Returned surveys were included in the analysis if at least $90 \%$ of the questions were answered. Surveys with missing responses were used to analyze items for non-response bias. To test for bias in nonresponses, we compared survey answers between those who completed all the questions with those who did not. An agreement above $75 \%$ or more was considered a majority opinion. Descriptive statistics were used in summarizing the data. The Chi-square test with post hoc analysis was used for comparisons. Two-tailed p values of 0.05 or less were considered as non-chance differences. Responses to the first three questions in the survey were compared to prior responses obtained from obstetricians-gynecologists with international origin during a prior survey-whereby they functioned as a historical control group (2). In order to compare responses between the two professional groups, a weighting was applied according to the overall response rate to both of the surveys, respectively. In order to determine the internal consistency of the survey, answers to questions 1,7 , and questions 2,5 , and 8 were used to compute reliability coefficients. A Cronbach's alpha of $>0.7$ was considered acceptable (3). The survey appeared to have good internal consistency $(\alpha 1=0.805, \alpha 2=0.875$, respectively). Data analysis and management was performed using IBM SPSS ${ }^{\circledR} 21$ (IBM Corp.; Armonk, NY, USA).

\section{Results}

Of 339 surveys distributed, 288 were returned, for an overall response of $84.9 \%$. Among the returned surveys, the completion rate was $96.1 \%$. In all of the surveys, more than $90 \%$ of the questions were answered. The non-response analysis did not indicate differences between those respondents who provided complete data and those with incomplete data. The job experience in years among clinicians and residents was $9 \pm 5$ and $3 \pm 1$, respectively. Comparison between the residents and clinicians indicated only limited differences in the responses to questions 1 and 6. Table 1 presents the responses to the survey questions 1 to 8 .

When analyzed according to decreasing levels of platelet count in questions 1 to 4, there was a significant inverse relation between the platelet count and the utilization of general anesthesia $(p<0.01)$. When compared to obstetricians-gynecologists working with a platelet count of $>100,000 / \mu \mathrm{L}$, anesthesiologists more often preferred general anesthesia $(\mathrm{p}<0.001)$ (Figure 1). In addition, when the platelet count ranged between 50,000 and $100,000 / \mu \mathrm{L}$, anesthesiologists preferred general anesthesia more often than the obstetric providers $(\mathrm{p}<0.001)$ (Figure 2). Below a platelet count of 50,000/ $\mu \mathrm{L}$ with severe thrombocytopenia, the responses between anesthesiologists and obstetric providers were similar (Figure 3).

For the last two survey questions (questions 9 and 10), we queried the future use of corticosteroid administration and ultrasound-guided regional anesthetic methods for patients complicated with se-

\section{Table 1. Responses to survey questions $1-8$}

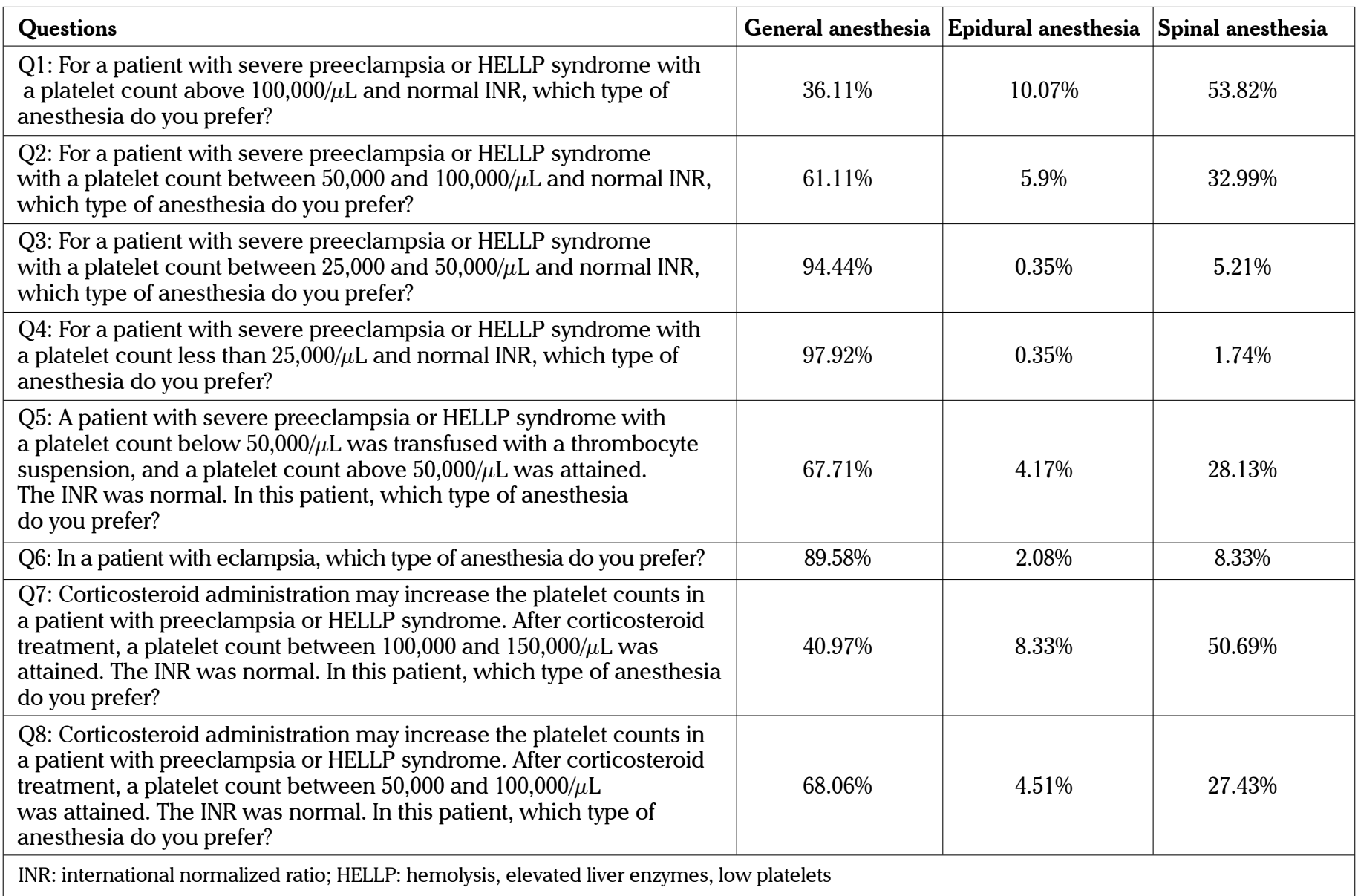


vere preeclampsia and HELLP syndrome. Half of the respondents agreed that corticosteroid administration via increasing platelet counts might increase the utilization of regional methods (Figure 4). Approximately half of the respondents thought that ultrasoundassisted regional anesthesia methods might decrease complication rates and might increase the procedural safety in this subset of patients (Figure 5).

\section{Discussion}

Our understanding of preeclampsia/HELLP syndrome has continued to significantly increase during recent decades. However, the two entities are still classified as a syndrome and not as a single disease entity. A syndrome, by definition, is any combination of signs and symptoms that is indicative of a process. Accordingly, the cause of preeclampsia/HELLP syndrome remains elusive (4). When faced with this dilemma in a clinical setting, clinicians try to improve the outcome for both the mother and

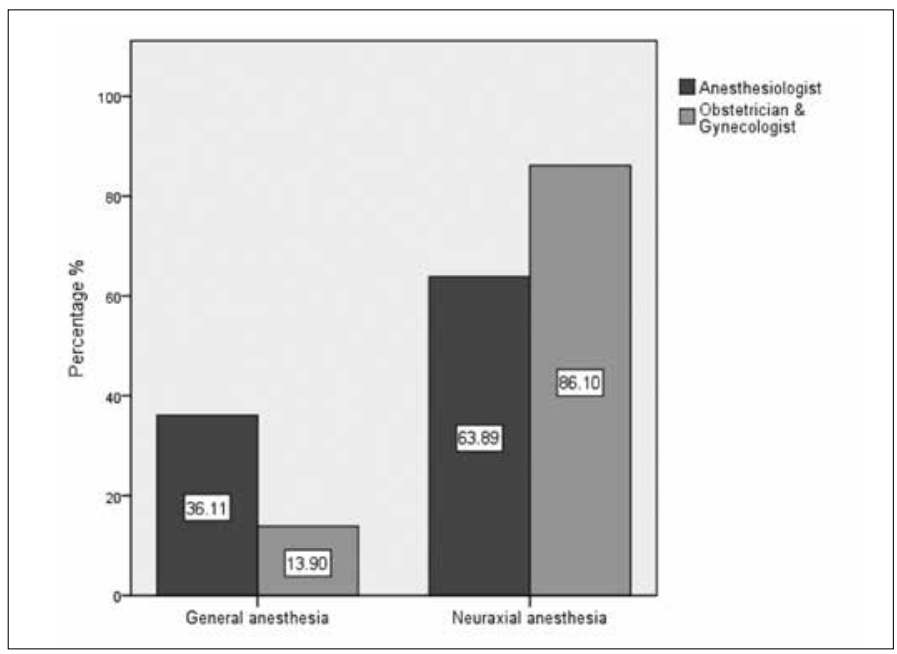

Figure 1. Preference in the type of anesthesia according to anesthesiologists and obstetricians-gynecologists for a platelet count above $100,000 / \mu \mathrm{L}$

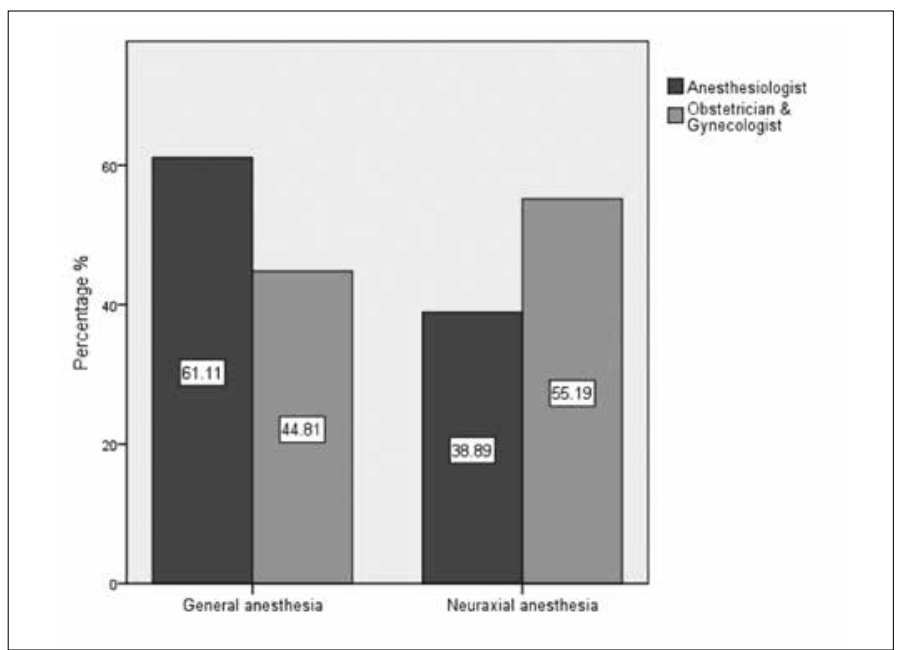

Figure 2. Preference in the type of anesthesia according to anesthesiologists and obstetricians-gynecologists for a platelet count between 50,000 and $100,000 / \mu \mathrm{L}$

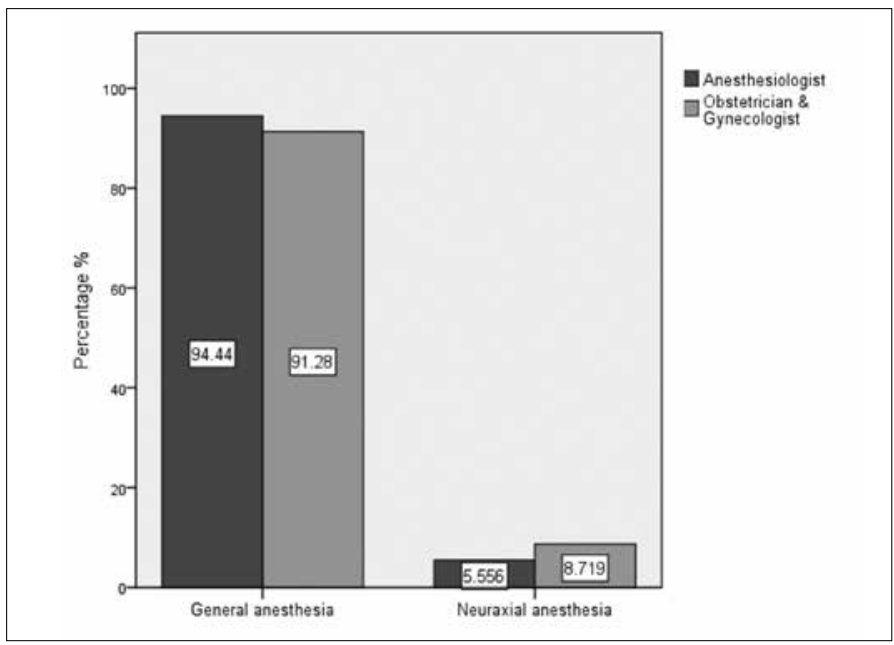

Figure 3. Preference in the type of anesthesia according to anesthesiologists and obstetricians-gynecologists for a platelet count below $100,000 / \mu \mathrm{L}$

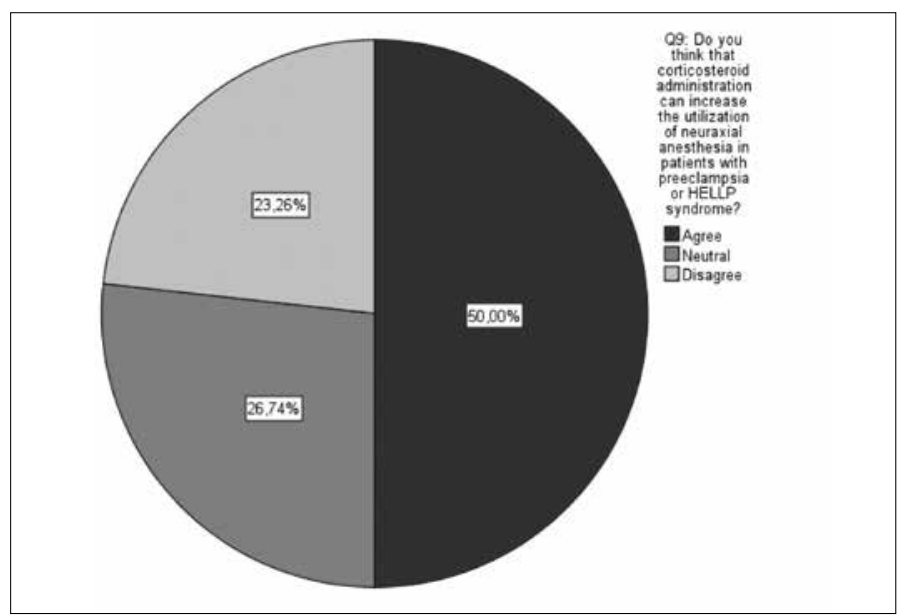

Figure 4. Thoughts on the potential of corticosteroid administration to increase the utilization of neuraxial anesthesia

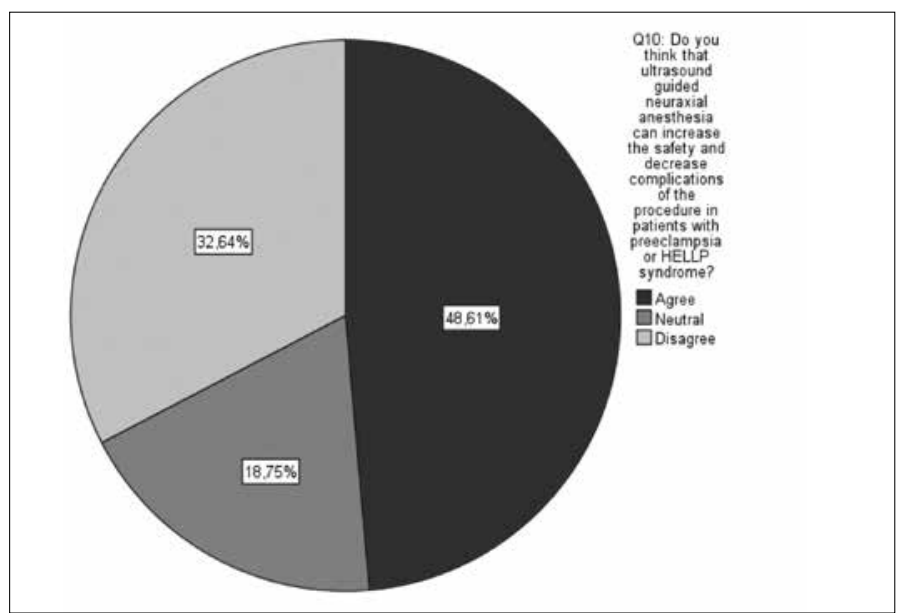

Figure 5. Thoughts on the potential of ultrasound-guided neuraxial anesthesia to decrease complications and increase the safety of the procedure 
baby. One excellent intervention for severe thrombocytopenia in the setting of HELLP syndrome has been high dose corticosteroids around the time of delivery. The peripartum period is a critical time, during which there are important opportunities to improve maternal-perinatal outcomes. Anesthetic management is no exception. Rapid resolution of preeclampsia and HELLP syndrome without mortality and with as little severe maternal morbidity as possible is thus highly desirable.

Either general or neuraxial methods may have some disadvantages in patients with preeclampsia. Due to upper airway edema, exacerbated hypertension, failed intubation, and aspiration, general anesthesia carries a significant risk of maternal death. Due to bleeding from the epidural veins, neuraxial anesthesia carries a significant risk of epidural hematoma and, consequently, paraplegia. Since the individualization of care is desirable, the choice of anesthetic method is directed by the maternal condition and laboratory parameters, which include the presence of eclampsia, severity of symptoms, platelet count and possibly complicating coagulopathy. For patients with preeclampsia who are not coagulopathic or thrombocytopenic, the risk of difficult or failed airway management and delayed recognition of maternal stroke during a general anesthetic are exceeded by the potential risk of adverse outcomes from neuraxial anesthesia (5). Moreover, maternal mortality statistics identify general anesthesia as a greater risk to parturients than neuraxial anesthesia $(6,7)$.

When the platelet count falls below $50,000 / \mu \mathrm{L}$ (severe thrombocytopenia), over $90 \%$ of the respondents prefer general anesthesia. However, respondents did not discriminate between platelet count ranges below $25,000 / \mu \mathrm{L}$ and $25,000 / \mu \mathrm{L}$ to $50,000 / \mu \mathrm{L}$ according to their clinical practice, as reflected by survey responses.

Over a platelet count of $50,000 / \mu \mathrm{L}$, opinions were divided between general and neuraxial methods. A significant $60 \%$ of the respondents preferred general anesthesia when the maternal platelet count was between 50,000 and $100,000 / \mu \mathrm{L}$. It was also interesting and illuminating that when the maternal platelet count exceeds $100,000 / \mu \mathrm{L}$, approximately $35 \%$ of the respondents still preferred general anesthesia.

Moreover, above a platelet count of $100,000 / \mu \mathrm{L}$, residents were more likely to prefer general anesthesia compared to clinicians $(p=0.02)$ (Figure 6). Below a platelet count of $100,000 / \mu \mathrm{L}$. the responses were similar between clinicians and residents. Accordingly, above a platelet count of $100,000 / \mu \mathrm{L}$, residents likely are being instructed to utilize neuraxial methods. When compared to obstetric providers, anesthesiologists were less eager to prefer neuraxial methods for obstetric patients with platelet counts above $50,000 / \mu \mathrm{L}$ and above $100,000 / \mu \mathrm{L}$ (Figure 1, 2). Although there appears to be consensus between anesthesiologists and obstetricians-gynecologists when maternal platelet counts decrease below $50,000 / \mu \mathrm{L}$, otherwise there exists a difference of opinion between the two specialties. Thus more evidence to guide practice and replace opinion is needed.

Altered hemostasis in preeclampsia is more often secondary to severe thrombocytopenia rather than to coagulopathy. Several studies have reported variable incidences of thrombocytopenia (platelet $<100,000 / \mu \mathrm{L}$ ), prolonged prothrombin time, and a prolonged activated partial thromboplastin time in patients with preeclampsia: $2 \%$ to $19 \%, 0 \%$ to $16 \%$, and $1.3 \%$ to $2.5 \%$, respectively (8-10). In one retrospective analysis, $8 \%$ of parturients exhibited both thrombocytopenia and coagulopathy (11). Studies investigating coagulation in women with preeclampsia using thromboelastography reported that if the platelet count was greater than $100,000 / \mu \mathrm{L}$ (absence of severe or moderate thrombocytopenia), there were no detectable coagulation abnormalities $(12,13)$. Platelet counts of less than $100,000 / \mu \mathrm{L}$ in women with preeclampsia may be associated with an impaired coagulation function and should prompt additional investigations of the coagulation status (12).

Instead of stratifying patients according to platelet count as a trigger to order coagulation tests, some recommend that it is practical and cost-effective to screen for both platelet count and coagulation studies at the same time $(14,15)$. As reflected from the current survey findings, a significant proportion of anesthesiologists in Turkey still prefer general anesthesia regardless of a normal coagulation profile and a platelet count exceeding $100,000 / \mu \mathrm{L}$. With a platelet count above $100,000 / \mu \mathrm{L}$, balancing the remote risk of maternal death due to epidural hematoma and choosing the greater risk of maternal death via general anesthesia in the clinical setting of preeclampsia/HELLP syndrome does not seem rational. Because there is not an established lower threshold for the platelet count to guarantee no potential for bleeding, practice guidelines simply indicate that the use of platelet count may reduce the risk of neuraxial anesthesia-related complications $(5,16,17)$. However, authors in the field generalize safety in the range of a platelet count somewhere between 50,000 and $100,000 / \mu \mathrm{L}$. In addition, the most cited cut-off is 70,000 to $80,000 / \mu \mathrm{L}(5,12,14)$. The real dilemma, therefore, lies with the management of patients with preeclampsia whose platelet counts range between 50,000 and $100,000 / \mu \mathrm{L}$. Neuraxial anesthesia is very safe in this platelet range, particularly when the coagulation profile is normal. In this range, two groups of patients raise special issues for clinical practice: patients with preeclampsia and HELLP syndrome. There are several reasons for this. First of all, the clinical course of HELLP syndrome is difficult to predict and variable in onset with usually a rapid progression of the syndrome $(18,19)$. Once initiated, patients with HELLP syndrome exhibit a 35-50\% decrease in platelet count per 24 hours and a mean daily reduction of $40,000 / \mu \mathrm{L}$ (18). Second, HELLP syndrome is a more potent and significant threat to the mother and fetus than preeclampsia. In the English literature, one patient series recorded 77 deaths among 2346 treated patients (ratio of 1:30), 53

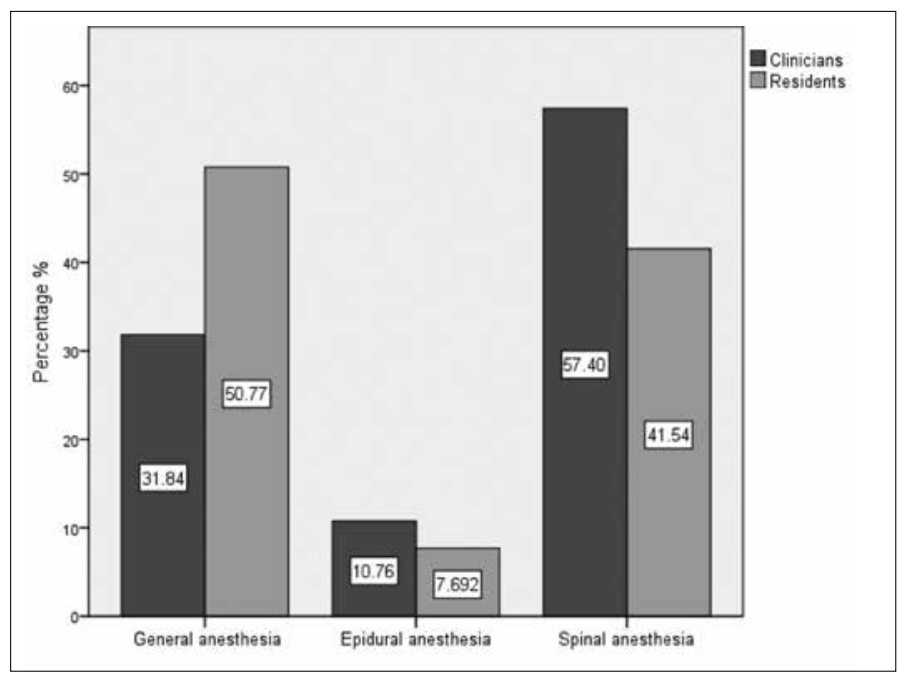

Figure 6. Preference in the type of anesthesia according to residents and clinicians for a platelet count above $100,000 / \mu \mathrm{L}$ 
strokes (ratio of 1:44), 178 patients with acute renal failure (1 for every 13 patients with HELLP syndrome), and just over 90 liver ruptures (20). Third, most spinal epidural hematomas occurred in patients with HELLP syndrome and not preeclampsia with no evidence of HELLP syndrome (5, 21-23). Moreover, epidural anesthesia was the preferred method in those complicated cases (24, 25). Vigil-De Gracia and colleagues reported 36 patients with HELLP syndrome with platelet counts below $100,000 / \mu \mathrm{L}$ who received regional anesthesia and no epidural hematoma was suffered by any of the patients (12 patients had platelet counts below 50,000/ $\mathrm{L}$ ) (26). None of those patients with HELLP syndrome in the study by Vigil-De Gracia (26) had disseminated intravascular coagulation and abnormal indices. Review of other series also revealed similar successful outcomes $(27,28)$. Fourth, laboratory parameters of patients with HELLP syndrome can continue to deteriorate postpartum, although they usually trend toward normal within 96 hours postpartum (18). Although a cut-off for the risk of spinal epidural hematoma has not been established, a platelet count of $40,000 / \mu \mathrm{L}$ and above has been assigned as the threshold above which there is no risk for postpartum bleeding from surgical sites in patients with HELLP syndrome (29). Spinal epidural hematoma and surgical site bleeding are not the same; therefore, the determined cut-off cannot be absolutely transposed for the risks of neuraxial anesthesia. However, in terms of maternal mortality and morbidity risk due to bleeding, they share a similar background.

In patients with severe preeclampsia and HELLP syndrome, the platelet count can be increased to $50,000 / \mu \mathrm{L}$ or above by two means separately or in combination: platelet pack transfusion and potent glucocorticoid administration. Antenatal corticosteroid administration has been reported to increase the platelet count; its use has been debated recently (30-32). It has also been shown to increase the utilization of neuraxial anesthesia among parturients (33). Thus, half of the survey respondents concurred that corticosteroid administration may increase the utilization of neuraxial anesthesia.

Moreover, respondents did not differentiate between the two methods (questions 5 and 8; Table 1) with regard to platelet counts and anesthesia application. However, a combined approach utilizing potent glucocorticoid administration and platelet pack transfusion may provide a more rapid and safer way to increase the platelet count to above $50,000 / \mu \mathrm{L}$ when cesarean surgery is needed to be performed quickly.

For patients with eclampsia, most respondents preferred general anesthesia (Table 1). Although general anesthesia is advocated in patients with eclampsia by some authors, there is minimal evidence to guide practice in the choice of anesthesia for women following an eclamptic convulsion (12). The hypertensive response to intubation has been identified as a direct cause of maternal mortality. Consequently, particular attention and extreme vigilance are required to ablate the hypertensive effect of intubation. Care must also be taken to avoid complications upon emergence from anesthesia, including hypertension, aspiration, and acute pulmonary edema (12). However, if the patient is stable with a normal level of consciousness and no neurological deficits, in the absence of other contraindications, neuraxial anesthesia is an acceptable choice (12).

The most dreaded complication of neuraxial anesthesia among patients with preeclampsia is the development of spinal epidural hematoma. The incidence of the complication is so low that it is difficult to comment on the methods to decrease its occurrence, such as ultrasound-guided neuraxial anesthesia (34). Theoretically, point-of-care ultrasound may decrease the number of attempts and increase the success of neuraxial anesthesia. Specifically, for patients with a borderline coagulation status, such as preeclampsia, ultrasonography may provide extra help and comfort to the anesthesiologist during the procedure

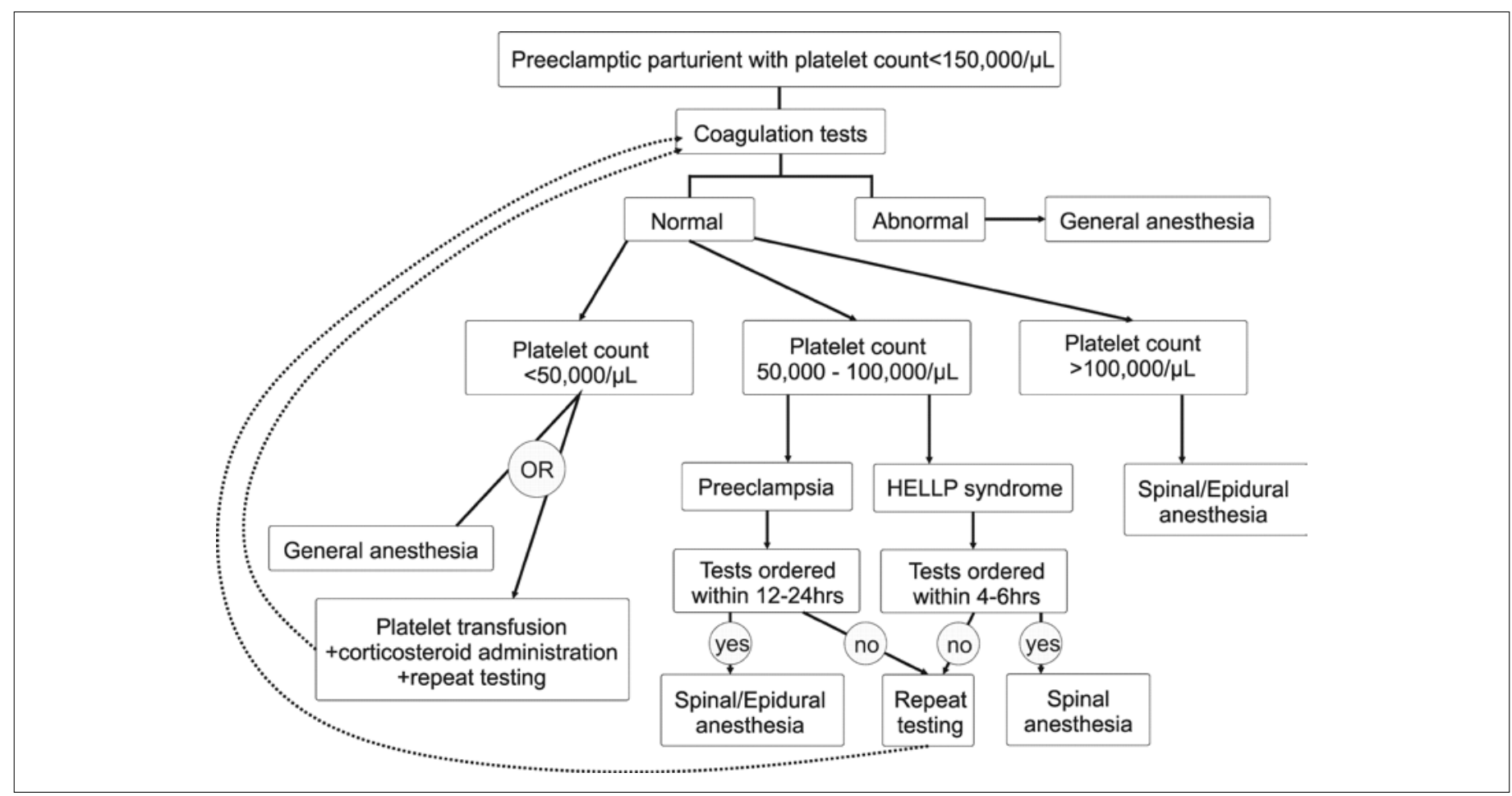

Figure 7. Proposed management algorithm 
(34). Accordingly, approximately half of the respondents agreed with this notion and potential (Figure 5).

In conclusion, more evidence from well-conducted prospective randomized trials is needed to clarify many of the issues raised in our survey and in clinical practice. In the interim, based on the available relevant recent literature, a management algorithm is proposed for this very specific at-risk patient group (Figure 7). The marked diversity in anesthesiology practice, as reflected by our survey results, underscores the need for more clarity in obstetric care, which can be principally gained through excellent clinical research.

Ethics Committee Approval: N/A.

Informed Consent: $N / A$.

Peer-review: Externally peer-reviewed.

Author Contributions: Concept - B.B., B.Ç., A.B.; Design - B.B., B.Ç., A.B.; Supervision - B.B., B.Ç., A.B., J.N.M.; Materials - B.B., B.Ç., A.B., S.A., L.K.; Data Collection and/or Processing - B.B., B.C.., S.A., L.K.; Analysis and/or Interpretation - B.B., B.C., A.B., S.A., L.K., J.N.M.; Literature Review - B.B., B.C.., A.B., S.A., L.K., J.N.M.; Writer - B.B., B.C.., A.B., J.N.M.; Critical Review - B.B., B.Ç., A.B., J.N.M.; Other - B.B., B.C., A.B., S.A., L.K., J.N.M.

Conflict of Interest: No conflict of interest was declared by the authors.

Financial Disclosure: The authors declared that this study has received no financial support.

\section{References}

1. Barton JR, Sibai BM. Gastrointestinal complications of pre-eclampsia. Semin Perinatol 2009; 33: 179-88. [Crossref]

2. Basaran A, Basaran M, Basaran B, Sen C, Martin JN. Controversial clinical practices for patients with preeclampsia or HELLP syndrome: a survey. J Perinat Med 2015; 43: 61-6. [Crossref]

3. Gliem JA, Gliem RR, editors. Calculating, interpreting, and reporting Cronbach's alpha reliability coefficient for Likert-type scales 2003: Midwest Research-to-Practice Conference in Adult, Continuing, and Community Education.

4. Redman CW. Preeclampsia: a multi-stress disorder. Rev Med Interne 2011; 32(Suppl 1): S41-4. [Crossref]

5. Henke VG, Bateman BT, Leffert LR. Focused review: spinal anesthesia in severe preeclampsia. Anesth Analg 2013; 117: 686-93. [Crossref]

6. Hawkins JL, Koonin LM, Palmer SK, Gibbs CP. Anesthesia-related deaths during obstetric delivery in the United States, 1979-1990. Anesthesiology 1997; 86: 277-84. [Crossref]

7. Mhyre JM, Riesner MN, Polley LS, Naughton NN. A series of anesthesia-related maternal deaths in Michigan, 1985-2003. Anesthesiology 2007; 106: 1096-104. [Crossref]

8. FitzGerald MP, Floro C, Siegel J, Hernandez E. Laboratory findings in hypertensive disorders of pregnancy. J Natl Med Assoc 1996; 88: 794-8.

9. Heilmann L, Rath W, Pollow K. Hemostatic abnormalities in patients with severe preeclampsia. Clin Appl Thromb Hemost 2007; 13: 285-91. [Crossref]

10. Sultan P, Butwick A. Platelet counts and coagulation tests prior to neuraxial anesthesia in patients with preeclampsia: a retrospective analysis. Clin Appl Thromb Hemost 2013; 19: 529-34. [Crossref]

11. Valera MC, Parant O, Vayssiere C, Arnal JF, Payrastre B. Physiologic and pathologic changes of platelets in pregnancy. Platelets 2010; 21: 587-95. [Crossref]

12. Dennis AT. Management of pre-eclampsia: issues for anaesthetists. Anaesthesia 2012; 67: 1009-20. [Crossref]

13. Sharma SK, Philip J, Whitten CW, Padakandla UB, Landers DF. Assessment of changes in coagulation in parturients with preeclampsia using thromboelastography. Anesthesiology 1999; 90: 385-90. [Crossref]

14. Ankichetty SP, Chin KJ, Chan VW, Sahajanandan R, Tan H, Grewal A, et al. Regional anesthesia in patients with pregnancy induced hypertension. J Anaesthesiol Clin Pharmacol 2013; 29: 435-44. [Crossref]
15. Metz J, Cincotta R, Francis M, DeRosa L, Balloch A. Screening for consumptive coagulopathy in preeclampsia. Int J Gynaecol Obstet 1994; 46: 3-9. [Crossref]

16. American Society of Anesthesiologists Task Force on Obstetric A. Practice guidelines for obstetric anesthesia: an updated report by the American Society of Anesthesiologists Task Force on Obstetric Anesthesia. Anesthesiology 2007; 106: 843-63.

17. Horlocker TT, Wedel DJ, Rowlingson JC, Enneking FK, Kopp SL, Benzon HT, et al. Regional anesthesia in the patient receiving antithrombotic or thrombolytic therapy: American Society of Regional Anesthesia and Pain Medicine Evidence-Based Guidelines (Third Edition). Regional anesthesia and pain medicine. 2010; 35: 64-101. [Crossref]

18. Martin JN, Jr., Rose CH, Briery CM. Understanding and managing HELLP syndrome: the integral role of aggressive glucocorticoids for mother and child. Am J Obstet Gynecol 2006; 195: 914-34. [Crossref]

19. Sibai BM, Barton JR. Dexamethasone to improve maternal outcome in women with hemolysis, elevated liver enzymes, and low platelets syndrome. Am J Obstet Gynecol 2005; 193: 1587-90. [Crossref]

20. Martin JN, Jr. Milestones in the quest for best management of patients with HELLP syndrome (microangiopathic hemolytic anemia, hepatic dysfunction, thrombocytopenia). Int $\mathrm{J}$ Gynaecol Obstet 2013; 121: 202-7. [Crossref]

21. Koyama S, Tomimatsu T, Kanagawa T, Sawada K, Tsutsui T, Kimura T, et al. Spinal subarachnoid hematoma following spinal anesthesia in a patient with HELLP syndrome. Int J Obstet Anesth 2010 19: 87-91. [Crossref]

22. Moen V, Dahlgren N, Irestedt L. Severe neurological complications after central neuraxial blockades in Sweden 1990-1999. Anesthesiology 2004; 101: 950-9. [Crossref]

23. Sibai BM, Taslimi MM, el-Nazer A, Amon E, Mabie BC, Ryan GM. Maternal-perinatal outcome associated with the syndrome of hemolysis, elevated liver enzymes, and low platelets in severe preeclampsia-eclampsia. Am J Obstet Gynecol 1986; 155: 501-9. [Crossref]

24. Lao TT, Halpern SH, MacDonald D, Huh C. Spinal subdural haematoma in a parturient after attempted epidural anaesthesia. Can J Anaesth 1993; 40: 340-5. [Crossref]

25. Yuen TS, Kua JS, Tan IK. Spinal haematoma following epidural anaesthesia in a patient with eclampsia. Anaesthesia 1999; 54: 350-4. [Crossref]

26. Vigil-De Gracia P, Silva S, Montufar C, Carrol I, De Los Rios S. Anesthesia in pregnant women with HELLP syndrome. Int $\mathrm{J}$ Gynaecol Obstet 2001; 74: 23-7. [Crossref]

27. Vercauteren M, Jacquemyn Y. Anaesthesia for caesarean section in patients with preterm HELLP syndrome: literature review, personal experience and possible guidelines. Actualitati in anestezie, terapie intensiva si medicina de urgenta; Timisoara, Romania 2008.

28. Tanaka M, Balki M, McLeod A, Carvalho JC. Regional anesthesia and non-preeclamptic thrombocytopenia: time to re-think the safe platelet count. Rev Bras Anestesiol 2009; 59: 142-53. [Crossref]

29. Roberts WE, Perry KG, Jr, Woods JB, Files JC, Blake PG, Martin JN, Jr. The intrapartum platelet count in patients with HELLP (hemolysis, elevated liver enzymes, and low platelets) syndrome: is it predictive of later hemorrhagic complications? Am J Obstet Gynecol 1994; 171: 799-804. [Crossref]

30. Basaran A, Basaran M, Sen C. Choice of glucocorticoid in HELLP syndrome - dexamethasone versus betamethasone: revisiting the dilemma. J Matern Fetal Neonatal Med 2012; 25: 2597-600. [Crossref]

31. Wallace K, Martin JN Jr, Tam Tam K, Wallukat G, Dechend R, Lamarca B, et al. Seeking the mechanism(s) of action for corticosteroids in HELLP syndrome: SMASH study. Am J Obstet Gynecol 2013; 208: 380.e1-8. [Crossref]

32. Woudstra DM, Chandra S, Hofmeyr GJ, Dowswell T. Corticosteroids for HELLP (hemolysis, elevated liver enzymes, low platelets) syndrome in pregnancy. Cochrane Database Syst Rev 2010: CD008148. [Crossref]

33. O'Brien JM, Shumate SA, Satchwell SL, Milligan DA, Barton JR. Maternal benefit of corticosteroid therapy in patients with HELLP (hemolysis, elevated liver enzymes, and low platelet count) syndrome: impact on the rate of regional anesthesia. Am J Obstet Gynecol 2002; 186: 475-9. [Crossref]

34. Ahmad M, Sinha AC. If you don't peep, you may shriek! Ultrasound for regional anesthesia in preeclampsia. J Anaesthesiol Clin Pharmacol 2013; 29: 431-2. [Crossref] 